I should like to point out that this method was tried by me well over a year ago, and the transilluminator that I designed for the purpose was shown at the Ophthalmological Congress in April, 1935, when I stated that although the idea appeared excellent in theory it was a complete and dismal failure in practice. I was led to make this remark for the following reasons: firstly, in one case, and one case only, did the hole show up by transillumination; secondly, in most cases when the transilluminator was in position it was found impossible to observe the retina through the pupil with an ophthalmoscope owing to lack of space.

I am very interested to read of the method of illumination used by Dr. van Heuven. In my instrment a 3-volt cystoscope lamp placed behind a solid cone of glass with a lens nearest the lamp was used; a right angle was bent in the cone, the surfaces of which were mirrored. By this means we eliminated as much loss of light as possible, although we found extreme difficulty in avoiding total reflection. The cone eventually used, and which I notice is advertised by Messrs. Hamblin in your January issue, was the result of many tried, and produced an intense spot of light at its apex, but the diffusion due to the light passing through the tissues destroyed its efficiency in locating the hole. As a transilluminator for ordinary purposes, i.e., the transillumination of the globe in cases of suspected neoplasm and for demonstrating atrophic holes in the iris it is quite satisfactory.

Yours faithfully,

T. Collyer Summers.

LONDON,

January 3, 1936

\title{
OBITUARY
}

\section{A. S. PERCIVAL}

WE record, with great regret, the death of Mr. Percival which occurred at his home, Shenley, Woking, on December 22, 1935.

Born in 1862, Archibald Stanley Percival was the son of the late Mr. Stanley Percival, of Woking. He was educated at Repton (1876-1880) and Trinity College, Cambridge, where he took his B.A. with 1st class honours in the Natural Sciences Tripos in 1884. He proceeded to his M.A. in 1888.

In 1884 he entered St. George's Hospital for his clinical work. He qualified M.R.C.S. in 1886, and took the M.B., B.Ch., Cantab., in 1888 . 
Percival's year at St. George's contained a large entry and he was not lucky enough to be elected to house office at his mother hospital. Instead he became house physician to the Hospital for Consumption, Brompton, and later, house surgeon to the Royal Westminster Ophthalmic Hospital. It was doubtless his experience here that led him to take up ophthalmology as his life's work. He settled at Newcastle-upon-Tyne and was elected ophthalmic surgeon to the City Hospital and to the Children's Hospital. In Newcastle he remained until he retired to his native place in 1928.

Percival was on the staff of and ultimately became senior surgeon to the Northumberland and Durham Eye Infirmary. During the War he served as ophthalmic surgeon to the Northern War Hospital. Practising, as he did, in a mining centre it was natural that he should have become an authority on miners' nystagmus. He held strong views on the dangers of in-breeding among the population of pit villages as being largely responsible for the condition of miners' nystagmus and was inclined to advocate measures which unfortunately were impracticable, as a cure.

From his school days Percival's mind gave evidence of a strong mathematical bent and his chief enjoyment in life was higher mathematics. Most of his ophthalmological writings thus dealt with the optical side of his specialty, and in this respect he held an unrivalled place among clinicians in this country. The writer remembers a short paper of his read many years ago at the Ophthalmological Society in which after having chalked on the black-board a formidable equation, he rather pathetically announced that he had been warned by the secretary to keep off higher mathematics!

Percival was a good friend to this journal for we referred optical matters to him, both while he was our representative for Newcastle on the General Editorial Committee, and after his retirement ; and we relied very largely on his judgment. He contributed numerous papers to our pages, on bifocal lenses, decentred lenses, prisms and other optical problems. His manuscript was not always easy to read and it became our custom always to send him a page revise proof in case any extra corrections were needed.

In 1899 he brought out a manual for students, entitled, "Optics." This, though nominally addressed to students, was far above the mental capacity of the average medical student, and was really a higher mathematical treatise. $\mathrm{He}$ also wrote a book on "Geometrical Optics," and on the Prescribing of Spectacles and Practical Integration.

Though he disclaimed any profound knowledge of the classics Percival read Greek with facility and he sent us for publication some years ago a delightful Greek epigram on an ophthalmic surgeon. 